\title{
Research on Building a Clean Government with the Participation of People Based on Corruption Perception
}

\author{
Lu Yang* \\ School of Government, \\ Beijing Normal University, \\ Beijing, China
}

\begin{abstract}
Empirical research shows that there is a significant positive correlation between people's corruption perception and satisfaction with a clean government. Their willingness to participate in building a clean government can enhance the correlation, but there is no obvious moderating effect for the people's participation in the practice of building a clean government. Further analysis shows that the main reasons for the insignificant moderating effect are their insufficient awareness on building a clean government, emphasis on the behavioral category in the way of participation, and poor ability in participating in building a clean government. On the basis of taking the influencing factors of people's corruption perception into consideration, their willingness to participate in building a clean government can be effectively promoted to be translated into practical actions by improving their awareness of the construction, improving their ability to participate in the construction and innovating the methods to participate in the construction.
\end{abstract}

Keywords-building a clean government, corruption perception, satisfaction with a clean government, people's participation

\section{INTRODUCTION}

Building good conduct and political integrity and fighting corruption complement each other. Great achievements have been made since the 18th CPC national congress. Public opinion polls show that people's satisfaction with anticorruption work has been rising. The "mass line" has long been proved to be an effective way of building good conduct and political integrity. It should guide the masses to actively participate in building orderly, rational and independent conduct and political integrity. [1] People's corruption perception is an important sign of the effectiveness of building good conduct and political integrity. The research shows that their corruption perception is affected by information channels, demographic variables, anti-corruption efforts, social trust level and other factors. [2] A low perception on corruption will weaken the authority and legitimacy of the government. Seligson, [3]Davis and Camp[4], Clausen and Keray[5] all confirmed that low perception on corruption can significantly reduce citizens' support for the legitimacy of political system and reduce their trust in public institutions. Therefore, the public's recognition, trust and satisfaction with the government can be judged from corruption perception.
General Secretary Xi Jinping said: "a political party, a political power, its future and destiny depends on the people's support. The people hate corruption, so we are firmly against it."[6] At present, through the legitimate channels and methods such as letters and visits and reports, "mass participation" has become an important force in building a clean government and anti-corruption. Only through participation can the public truly feel the clean situation in government and its officials and its changes. In turn, people's corruption perception can directly reflect the results of building a clean government and the room for improvement. Under the background of ever-improving the design of the top-level construction of a clean government, from the perspective of "their corruption perception", this paper explores how to enhance people's willingness, ability and action to participate in building a clean government by taking "the participation of the masses" as the moderating variable, which is consistent with the requirements of the mass line of our party. It is a new idea to deepen the building of a clean government in the new era.

\section{The Formation AND ENHANCEMENT OF PEOPLE'S Corruption Perception Cannot Do Without People}

\section{A. Research hypothesis, data acquisition and statistic result}

People's corruption perception is an important indicator for judging the effectiveness of anti-corruption and clean government construction. There are two bases for the formation of people's corruption perception. One is their general impression on a clean government; the other is their cognition on building a clean government. Since "mass participation" is crucial to the formation and improvement of their corruption perception, thus it can be used as a moderator variable to explore the influencing factors of corruption perception. By doing so, it can improve the effectiveness of the public participation in building a clean government, and in turn enhance their corruption perception and satisfaction with government. 3 hypotheses are put forward surrounding the research objectives.

Hypothesis 1: With other conditions unchanged, people's corruption perception is positively correlated with the satisfaction with a clean government. The higher the public awareness on the building a clean government is, the higher of the satisfaction with a clean government is, vice versa. 
Hypothesis 2: With other conditions unchanged, the willingness of the masses to participate in building a clean government has a moderating effect on their corruption perception.

Hypothesis 3: With other conditions unchanged, people's participation in building a clean government has a moderating effect on people's corruption perception.

Based on the "corruption perception index" in the "index system of performance evaluation on a clean government" [7], the "questionnaire of people's corruption perception" is compiled. Based on the American Customer Satisfaction Index
(ACSI) and the "public satisfaction assessment model on government services" by Sheng Mingke and Liu Guizhong, [8] "the questionnaire of satisfaction assessment on a clean government "is compile by focusing on "anti-corruption". The questionnaire also includes the willingness to participate in building a clean government, the willingness to participate in its practice, as well as demographic variables such as gender, age and education background. A total of 350 questionnaires are distributed and 310 are effectively collected, with a collection rate of $88.57 \%$.

The result of questionnaire is shown as TABLE I and TABLE II:

TABLE I. CORRELATION OF MAIN VARIABLES (N-310)

\begin{tabular}{|l|l|l|l|l|l|l|l|l|}
\hline Variable & 1 & 2 & 3 & 4 & 5 & 6 & 7 & 8 \\
\hline 1 Gender & 1 & & & & & & \\
\hline 2 Age & $-.364^{* *}$ & 1 & & & & & \\
\hline 3 Education Background & $.343^{* *}$ & $-.516^{* *}$ & 1 & & & & & \\
\hline 4 Occupation & .024 & $-.183^{* *}$ & $-.140^{*}$ & 1 & & & & \\
\hline 5 People's Corruption Perception & -.098 & $.162^{* *}$ & $-.168^{* *}$ & $-.218^{* *}$ & 1 & & & \\
\hline 6 Satisfaction on a Clean Government & $-.174^{* *}$ & $.186^{* *}$ & $-.224^{* *}$ & $-.214^{* *}$ & $.717^{* *}$ & 1 & & \\
\hline 7 People's Willingness to Participation & -.096 & -.095 & $.296^{* *}$ & $-.144^{*}$ & -.065 & -.040 & 1 & \\
\hline 8 People's Practice & $.292^{* *}$ & $-.188^{* *}$ & $.127^{*}$ & $.155^{* *}$ & -.060 & -.033 & $-.238^{* *}$ & \\
\hline
\end{tabular}

TABLE II. CORRELATION BETWEEN EACH DIMENSION OF CORRUPTION PERCEPTION AND SATISFACTION WITH A CLEAN GOVERNMENT

\begin{tabular}{|l|c|c|c|c|c|}
\hline Variable & 1 & 2 & 3 & 4 & 5 \\
\hline 1 People's Corruption Perception & 1 & & & & \\
\hline 2 Cognition on Building a Clean Government & $.465^{* *}$ & 1 & & & \\
\hline 3 Tolerant Degree of Corruption & .039 & .105 & 1 & & \\
\hline 4 Personal Practice in Anti-corruption & $.463^{* *}$ & $.486^{* *}$ & .039 & 1 & \\
\hline 5Satisfaction with a Clean Government & $.659^{* *}$ & $.540^{* *}$ & $.503^{* *}$ & $.126^{*}$ & 1 \\
\hline
\end{tabular}

TABLE I shows that there is a significant positive correlation between people's corruption perception and the satisfaction with a clean government, and the correlation reaches $0.717 \quad(\mathrm{p}<0.01)$. With the improvement of people's corruption perception, the overall satisfaction with clean government has been improved. TABLE II shows that the satisfaction with a clean government is significantly positively correlated with people's corruption perception, the cognition of building a clean government, personal practice, and the tolerance of corruption at the level of 0.05 .

\section{B. The moderating effect of people's participation on the corruption perception is differentiated}

People's participation in anti-corruption and building a clean government includes two aspects: "willingness to participation" and "practice". The willingness is the premise of participation in building a clean government, and participation in practice is the result and reflection of the willingness, which have a different moderating effect on people's corruption perception (TABLE III and TABLE IV).

TABLE III. THE MODERATING EFFECT OF THE WILLINGNESS TO PARTICIPATE IN BUILDING A CLEAN GOVERNMENT ON CORRUPTION PERCEPTION AND ON ITS PERCEPTION AND SATISFACTION WITH A CLEAN GOVERNMENT

\begin{tabular}{|l|c|c|c|c|c|c|}
\hline \multirow{2}{*}{ Variable } & \multicolumn{3}{|l|}{ Satisfaction on a Clean Government } \\
\cline { 2 - 7 } & \multicolumn{2}{|c|}{ Model 1 } & \multicolumn{2}{|c|}{ Model 2 } & \multicolumn{2}{|c|}{ Model 3 } \\
\cline { 2 - 7 } & B & Sig & B & Sig & B & sig \\
\hline Constant Quantity & 21.222 & .000 & 4.334 & .013 & 5.119 & .004 \\
\hline Gender & -.649 & .108 & -.529 & .078 & -.560 & .061 \\
\hline Age & -.055 & .851 & -.091 & .672 & -.116 & .587 \\
\hline Education Background & -.875 & .001 & -.416 & .030 & -.457 & .017 \\
\hline Occupation & -.764 & .000 & -.256 & .051 & -.243 & .062 \\
\hline People's Corruption Perception & & & .488 & .000 & .468 & .000 \\
\hline Willingness to Participate in Building a Clean Government & & & .057 & .738 & .057 & .737 \\
\hline Interaction Item & & & & & \\
\hline
\end{tabular}




\begin{tabular}{|c|c|c|c|c|}
\hline \multicolumn{5}{|c|}{ Cont. to TABLE III } \\
\hline $\begin{array}{l}\beta \text { coefficient } \\
\text { (corruption perception * willingness to participate) }\end{array}$ & & & .070 & .021 \\
\hline 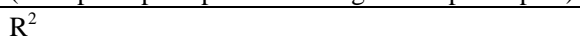 & .121 & $\frac{1}{.538}$ & \multicolumn{2}{|c|}{.546} \\
\hline$\Delta \mathrm{R}^{2}$ & .121 & .417 & \multicolumn{2}{|c|}{.008} \\
\hline $\mathrm{N}$ & 310 & 310 & \multicolumn{2}{|c|}{310} \\
\hline
\end{tabular}

TABLE IV. THE MODERATING EFFECT OF THE PRACTICE IN PARTICIPATING IN BUILDING A CLEAN GOVERNMENT ON CORRUPTION PERCEPTION AND ON ITS PERCEPTION AND SATISFACTION WITH A CLEAN GOVERNMENT

\begin{tabular}{|c|c|c|c|c|c|c|}
\hline \multirow{3}{*}{ Variable } & \multicolumn{6}{|c|}{ Satisfaction on a Clean Government } \\
\hline & \multicolumn{2}{|c|}{ Model 1} & \multicolumn{2}{|c|}{ Model 2} & \multicolumn{2}{|c|}{ Model 3} \\
\hline & $\mathrm{B}$ & Sig & B & Sig & $\mathrm{B}$ & sig \\
\hline Constant Quantity & 21.222 & .000 & 4.464 & .007 & 4.566 & .006 \\
\hline Gender & -.649 & .108 & -.528 & .084 & -.537 & .079 \\
\hline Age & -.055 & .851 & -.092 & .670 & -.086 & .688 \\
\hline Education Background & -.875 & .001 & -.402 & .030 & -.404 & .029 \\
\hline Occupation & -.764 & .000 & -.258 & .050 & -.260 & .048 \\
\hline People's Corruption Perception & & & .487 & .000 & .484 & .000 \\
\hline Practice in Participating in Building a Clean Government & & & .058 & .784 & .042 & .845 \\
\hline \multicolumn{7}{|l|}{ Interaction Item } \\
\hline $\begin{array}{l}\beta \text { coefficient } \\
\text { (corruption perception * willingness to participate) }\end{array}$ & & & & & -.021 & .677 \\
\hline $\mathrm{R}^{2}$ & \multicolumn{2}{|c|}{.121} & \multicolumn{2}{|c|}{.538} & \multicolumn{2}{|c|}{.538} \\
\hline$\Delta \mathrm{R}^{2}$ & \multicolumn{2}{|c|}{.121} & \multicolumn{2}{|c|}{.417} & \multicolumn{2}{|c|}{.000} \\
\hline $\mathrm{N}$ & \multicolumn{2}{|c|}{310} & \multicolumn{2}{|c|}{310} & \multicolumn{2}{|c|}{310} \\
\hline
\end{tabular}

1) The willingness of people's participation has a positive moderating effect on corruption perception.

In order to avoid the influence of collinearity, the "corruption perception" and "people's willingness to participating in building a clean government" is decentralized, and the product of the decentralization is an interactive term. In the linear test, the VIF value in the model $(\mathrm{VIF}<5)$ meets the requirements, proving that there is no serious collinear problem in the model. The results show that the Model 3 has an incremental effect compared with the Model 2, which means that the stronger the willingness of the public to participate in building a clean government, the more significant the correlation between the corruption perception and the satisfaction with clean government. Hypothesis 2 is true.

2) The moderating effect of corruption perception is insignificant for people's participation in the practice.

Similar to the test of moderating effect of people's willingness, hierarchical regression is used to test the VIF value of the model $(\mathrm{VIF}<5)$ to ensure that there was no serious collinlining problem in the model. The results show that when the interaction term between corruption perception and people's participation in practice is added, the $\beta$ coefficient of interaction term is -0.021 , with its sig value is 0.677 , and its $\mathrm{R}^{2}$ value is 0.000 . The interaction term has extremely weak influence and low correlation. Therefore, it can be judged that the moderating effect is insignificant for peoples' participation in building a clean government and the correlation between corruption perception and satisfaction with a clean government. Hypothesis 3 is not true.

\section{People's Corruption Perception Is AfFected by the GAP BETWEEN THEIR PARTICIPATION IN PRACTICE AND THEIR WILLINGNESS}

It has been proved above that "people's willingness to participate in building a clean government" can enhance their corruption perception and thus improve the satisfaction with a clean government. However, it is insignificant of the moderating effect of "people's participation in building a clean government" on corruption perception and the correlation between corruption perception and satisfaction. According to the statistical results of the random survey in the form of the questionnaire, the direct reasons for the gap between their willingness and practice is due to insufficient cognition on building a clean government, the lack of efficient ways to participate and poor ability in participation.

\section{A. Lack of cognition on building a clean government}

There is a certain gap between the survey results and the current anti-corruption action and the achievements of building good conduct and political integrity. Not all people can take practical and effective actions to participate in it. The induced theory in psychology believes that external stimulus will play an important role in evoking behavior. And education and publicity can effectively enhance the public's awareness of a clean government, thus promoting more people to participate in building a clean government. However, at present, the education and publicity of building a clean government in China are not perfect. There are problems such as undiversified education form and lack of pertinence, etc., [9] which makes people unable to receive effective external stimulation. Their willingness to participate in it cannot be effectively translated into action, thus affecting the corruption perception and their satisfaction with clean government. 


\section{B. Diversified ways for people to build a clean government} with excessive emphasis on actions.

Respondents said that there are many ways to participate in building a clean government which can be divided into "emphasis on action" and "substantial action". Among them, $20 \%$ people concern about the building a clean government and information of anti-corruption and 27\% study and spread related knowledge on building a clean government. (Fig. 1). In general, people are mostly concerned about actions in the practice of participating in building a clean government, which is conducive to improving their awareness and willingness to participate in it. Under certain conditions, it will be transformed into "the culture of clean government" or "psychology of clean government", which corresponds with laws, regulations and other formal systems of anti-corruption, thus improving the effect of building a clean government. However, at the present stage, the poor code of conduct, inefficient communicative ways to participate and insufficient systems affect people's participation.

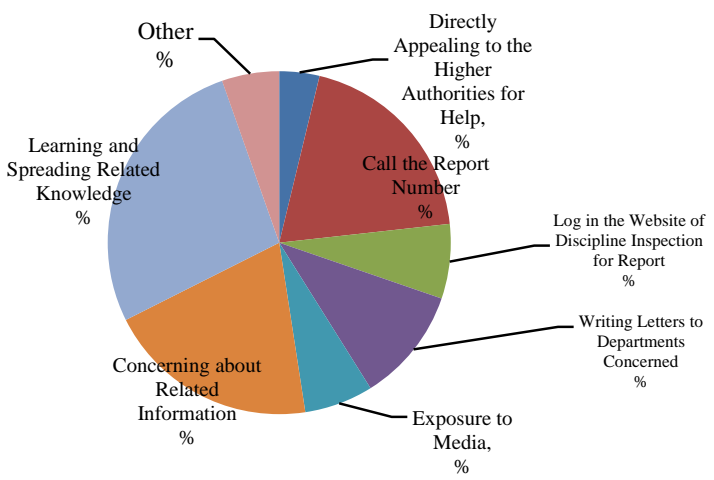

Fig. 1. Summary of diversified ways for people to participate in building a clean government

\section{Poor ability of people's participation in building a clean government.}

"A ladder of citizen participation" stresses that there are three stages with eight ladders for people's participation, that is, manipulation, guidance, notification, consultation, persuasion, cooperation, authorization and public control. [10]Zhou Zhiren and [11]Xiao Junqi et al [12] add five ladders into this theory: no participation, ineffective participation, limited participation, high participation and dominated participation. From the perspective of the respondents' participation in building a clean government, they are basically in a state of transition from a lower stage to a higher stage which is manifested as irregular participation, willingness exceeding action, and lack of rationality, etc., which not only affects their corruption perception, but also affects the effectiveness of the participation in building a clean government.

\section{Promoting People to Participate in BuILding A CleAn GOVERnMENT Through CORRUPtion PERCEPTION}

To improve and enhance people's participation in building a clean government, we must encourage them to translate their willingness, awareness or motivation into, especially into substantive action.

\section{A. Enhancing peoples' cognition on building a clean government.}

First, it should fully disclose information on building a clean government and anti-corruption in time. Governments at all levels should disclose such information through Weibo, WeChat, authoritative public accounts, forming a good social clean culture atmosphere and clean mind. [13] Second, through the widespread publicity, it should let people realize that a clean government has a close relationship with their own interests. Their participation in the practice of building a clean government should start from trivial matters.

\section{B. Improving people's ability in building a clean government.}

According to the survey, there is no lack of willingness and motivation to participate in building a clean government. However, due to the limitations of people's cultural level, experience and employment experience, they are mostly in the "invalid participation" and "limited participation" levels in the participation ladder. First, it should let people know how to participate in building a clean government and effectively avoid frustration and irrational participation. Second, it should improve the rules and regulations governing public participation in building a clean government. We should guide them to effectively participate in building a clean government, encourage them to participate in it in an orderly, standardized and efficient way, and maximize the effectiveness of their participation.

\section{Innovating ways to participate in building a clean government.}

Internet technology and various information communication platforms provide favorable conditions for the innovation of public participation in building a clean government. Take the successful mode of people's participation--"residents in Chaoyang district" as an example, "Residents in Chaoyang district" became famous for helping police to arrest many stars who take drug. They have become an important source to provide clues for local public security organs, which is worth promoting in the field of public participation in building a clean government. Additionally, it should develop an APP for building a clean government, timely release information on clean government and anticorruption and verified public report information in the news section of the home page so as to reduce the cost of public participation and smooth the channel for public participation.

\section{CONCLUSION}

"Mass line" and "mass participation" must be adhered to in building good conduct and political integrity and fighting corruption. People's corruption perception and satisfaction with a clean government measure the effectiveness of building good conduct and political integrity. Empirical research shows that there is a significant positive correlation between the corruption perception and the satisfaction with a clean government. Their willingness to participate in building a clean government can further enhance such correlation, but there is no significant moderating effect of the practice on participating in building a clean government on the correlation. Further analysis shows that the main reasons for the insignificant moderating effect are their insufficient awareness 
on building a clean government, emphasis on the behavioral category in the way of participation, and poor ability in participating in building a clean government, which are also the reasons of the gap between their willingness and practice that is hard to further improve corruption perception.

\section{REFERENCE}

[1] Zhou Wei, Li Zhonghe: The Change in History and Concept: Review and Outlook on the Mode of People's Participation in Building a Clean Government in China, Socialism Studies, 2014 (6).

[2] Sun Zongfeng, Yang Litianqing: How to Influence Public Perception on Corruption by "Taking out Tigers": Based on QuasiExperimental Study in Guangdong Province, Journal of Public Administration, 2016(3).

[3] Seligson, M. A., The Impact of Corruption on Regime Legitimacy: A Comparative Study of Four Latin American countries, The Journal of Politics, Vol.64, No.2, 2002, PP. 408-433.

[4] Davis C. L., Camp R. A. \& Coleman K M., The Influence of Party Systems on Citizens' Perceptions of Corruption and Electoral Response in Latin America, Comparative Political Studies, Vol.37, No.6, 2004, PP. 677-703.
[5] Clausen B., Kraay A. \&Nyiri Z., Corruption and Confidence in Public Institutions: Evidence from a Global Survey, The World Bank Economic Review, Vol.25, No.2, 2011, PP.212-249.

[6] Xi Jingping overthrows Five Arguments on Anti-Corruption by Taking Out Tigers and Swatting Flies in Three Years, People's Daily, 2016-1024

[7] Ning Xing, Hao Lin: Study on the Construction of Index System to Evaluating the Performance of A Clean Government, Theory Monthly, 2012(12)

[8] Sheng Mingke, Liu Guizhong: Research on Model and Methods of Assessment on People's Satisfaction on Government Service, Hunan Social Science, 2006(6).

[9] Li Xiaochun, Wang Xiangshui, Gao Weihong: On Problems and Solutions of Clean Culture Education in Institutions of High Learning, Education Exploration, 2010(8)

[10] Arnstein Sherry, R. A Ladder of citizen Participation, Journal of the American Institute of Planners, Vol.35, No.4, 1969, PP.216-224.

[11] Zhou Zhiren: Public Participation in Assessment of Governmental Performance: the Practical Course and Outlook in China, Chinese Public Administration, 2008(1).

[12] Xiao Junqi: Study on the Mechanism of Public Participation in the Assessment of A Clean Government, Anti-Corruption and Integrity Culture Studies, 2014(4)

[13] Cheng Huixia: On Anti-Corruption Mechanism of Inspection Group and Its Enhancement Path, Journal of Nanjing Normal University (social and science version), 2017(4). 